\title{
Treatment of Massive Low-Grade Chondrosarcoma of Nasal Septum with Helical Tomotherapy: A Case Report
}

\author{
Hamit Basaran ${ }^{*}$, Timur Koca1, Sibel Karaca1, Ozlem Eser Kılınc¹, Fikriye Gul Karauc¹, Okan Özdemir¹, \\ Ozan Kuduban², Arzu Tatar ${ }^{3}$, Sare Şipal ${ }^{4}$
}

${ }^{1}$ Department of Radiation Oncology, Regional Training and Research Hospital, Erzurum, Turkey

${ }^{2}$ Department of Otorhinolaryngology, Regional Training and Research Hospital, Erzurum, Turkey

${ }^{3}$ Department of Otorhinolaryngology, Ataturk University Faculty of Medicine, Erzurum, Turkey

${ }^{4}$ Department of Pathology, Ataturk University Faculty of Medicine, Erzurum, Turkey

Email: ^drhbasaran@gmail.com

How to cite this paper: Basaran, H., Koca, T., Karaca, S., Kilınc, O.E., Karauc, F.G., Özdemir, O., Kuduban, O., Tatar, A. and Şipal, S. (2016) Treatment of Massive LowGrade Chondrosarcoma of Nasal Septum with Helical Tomotherapy: A Case Report. International Journal of Medical Physics, Clinical Engineering and Radiation Oncology, 5, 263-269.

http://dx.doi.org/10.4236/ijmpcero.2016.54026

Received: September 23, 2016

Accepted: November 4, 2016

Published: November 7, 2016

Copyright $\odot 2016$ by authors and Scientific Research Publishing Inc. This work is licensed under the Creative Commons Attribution International License (CC BY 4.0).

http://creativecommons.org/licenses/by/4.0/

(c) (i) Open Access

\begin{abstract}
Chondrosarcomas are malignant bone tumors which develop as a cartilaginous differentiation of primary mesenchymal cells and the second most frequently seen malignant tumor of the bone after osteosarcoma. These malignancies are slowly growing non-epithelial tumors with unknown etiology and most frequently seen during the 4 decades of life. They are frequently localized on pelvis, ribs and long bones. Nasal septum CSs are very rarely seen malignancies. They originate from septal mucosa or cartilage and it is difficult to make a diagnosis unless they reach a certain size. A few cases of CSs with nasal septum have been reported in the literature. In cases of CSs, surgery is the gold standard treatment modality; however in surgically unresectable cases or close to margins, radiotherapy plays a significant role in primary and adjuvant treatment. Based on the position of the tumor in head and neck and extremely closeness of the tumor to vital organs as optic nerve, chiasm and brain, image guided-intensity modulated radiation therapy (IG-IMRT) becomes very effective and reliable modalities and may be a favorable treatment alternative.
\end{abstract}

\section{Keywords}

Chondrosarcoma, Image Guided, Intensity Modulated Radiation Therapy

\section{Introduction}

Chondrosarcomas (CSs) are malignant bone tumors which develop as a cartilaginous differentiation of primary mesenchymal cells. It is the second most frequently seen ma- 
lignant tumor of the bone after osteosarcoma and rarely (1\% - 12\%) observed in head and neck (HN) region. In this region, it has been reported frequently in larynx, maxilla and skull base and rarely seen in nasal cavity [1].

Primary treatment of HN CSs is radical surgery [2]. Neck dissection is not recommended because of low rates of regional lymph node involvement (5.6\%) [1]. However, in surgically unresectable cases, chemotherapy and radiotherapy are main components of treatment. Some authors assert that since CSs are not a radiosensitive tumor, radiotherapy has no place in primary and adjuvant therapy [3]; however, some of them suggest that radiotherapy provides acceptable outcomes [4] [5]. Besides, some authors think that different radiotherapy techniques such as Intensity Modulated Radiation Therapy (IMRT) or Proton Beam Radiation Therapy may yield diverse treatment outcomes [6] [7]. In this report, a patient with a diagnosis of inoperable low-grade CSs arising from nasal septum, which was treated using HT device, was presented.

\section{Case Report}

A 71-year-old female patient consulted to outpatient clinic of Ear-Nose and Throat in 2013 with complaints of difficult nasal breathing, nasal stuffiness for nearly 10 years, gradual worsening of vision of the right eye and diplopia for 6 months. Anterior rhinoscopic examination detected a mass completely filling the nasal cavity. MRI of the patient demonstrated a mass in the left nasal cavity, extending into anterior cranial fossa, basis cranii, right orbita and left ethmoidal sinus with hypointense intensity on T1-weighted and heterogenous intensity on T2 weighted contrast-enhanced images (Figure 1). The mass contained irregular calcifications. Histopathological examination of the biopsy material excised from nasal cavity revealed tumoral mass formed by atypical chondrocytes demonstrating nuclear hyperchromasia and binucleationin the chondroid matrix, which was reported as low-grade CSs (Figure 2). Before initiation of

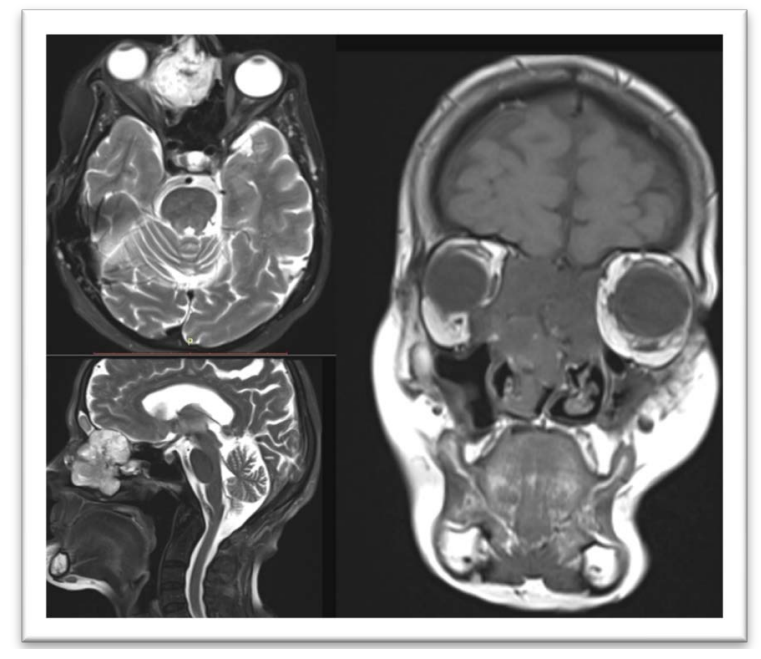

Figure 1. MR image of the mass with heterogenous contrast uptake which invaded left nasal cavity, anterior cranial fossa, skull base, right orbita and left ethmoidal sinuses. 


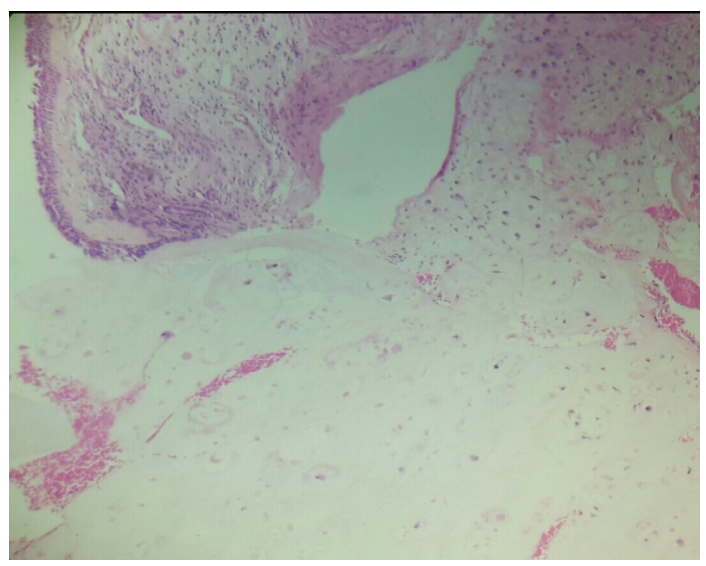

Figure 2. Atypical chondrocytes in chondroid matrix which invaded nasal mucosa $2(\mathrm{H} \& \mathrm{E} \times 200)$.

external radiotherapy visual field examination performed by the clinic of Eye Diseases, disclosed decreased visual acuity of the right eye and diplopia. The patient was evaluated in our clinic, treatment using HT device was decided. Tumor volume, clinical target volume and critical organs were contoured. Extreme proximity of the tumor to vital organs such as optic nerve, optic chiasm and brain and its invasion into the right orbita and skull base made treatment planning process complicated. For better protection of critical organs; treatment plan was prepared using a Simultaneous Integrated Boost technique (Figure 3). Treatment planning of the patient was created using HT planning system (Accuray Inc., Madison, USA). In this planning a field width of 2.5 $\mathrm{cm}$, a pitch of 0.287 and a modulation factor of 2.0 were used during optimization and dose calculation (Table 1). The patient was treated to $64 \mathrm{~Gy}$ in 32 fractions using HT device.

Control examination performed at 3 Month after radiotherapy demonstrated that visual acuity of the patient's right eye and diplopia recovered almost complete. Partial regression in the dimensions of the lesion was observed on MRI obtained at 6 Month, while a marked regression was detected in the dimensions of the lesion on MRI obtained at 18 Month (Figure 4). The patient is still followed up by us and at control examination in June 2015 the patient did not report any complaint.

\section{Discussion}

Chondrosarcomas are locally aggressive tumors, which rarely metastasize, and symptoms may change according to the size and location of the tumor. In localized HN CSs nodal and distant metastasis is rare [8]. CSs originating from nasal septum may generally manifest nonspecific symptoms as nasal obstruction, epistaxis, nasal discharge, in advanced cases with invasion into skull base, it may lead to symptoms of diplopia, proptosis, facial pain, headache, cranial nerve deficits, loss of vision and otalgia [9] [10]. Our patient complained of nasal obstruction gradually increasing for nearly 10 years and decreased visual acuity of the right eye persisting for the last 6 months and diplopia. In cases with CSs arising from nasal septum, as it is seen in our patient, disease 


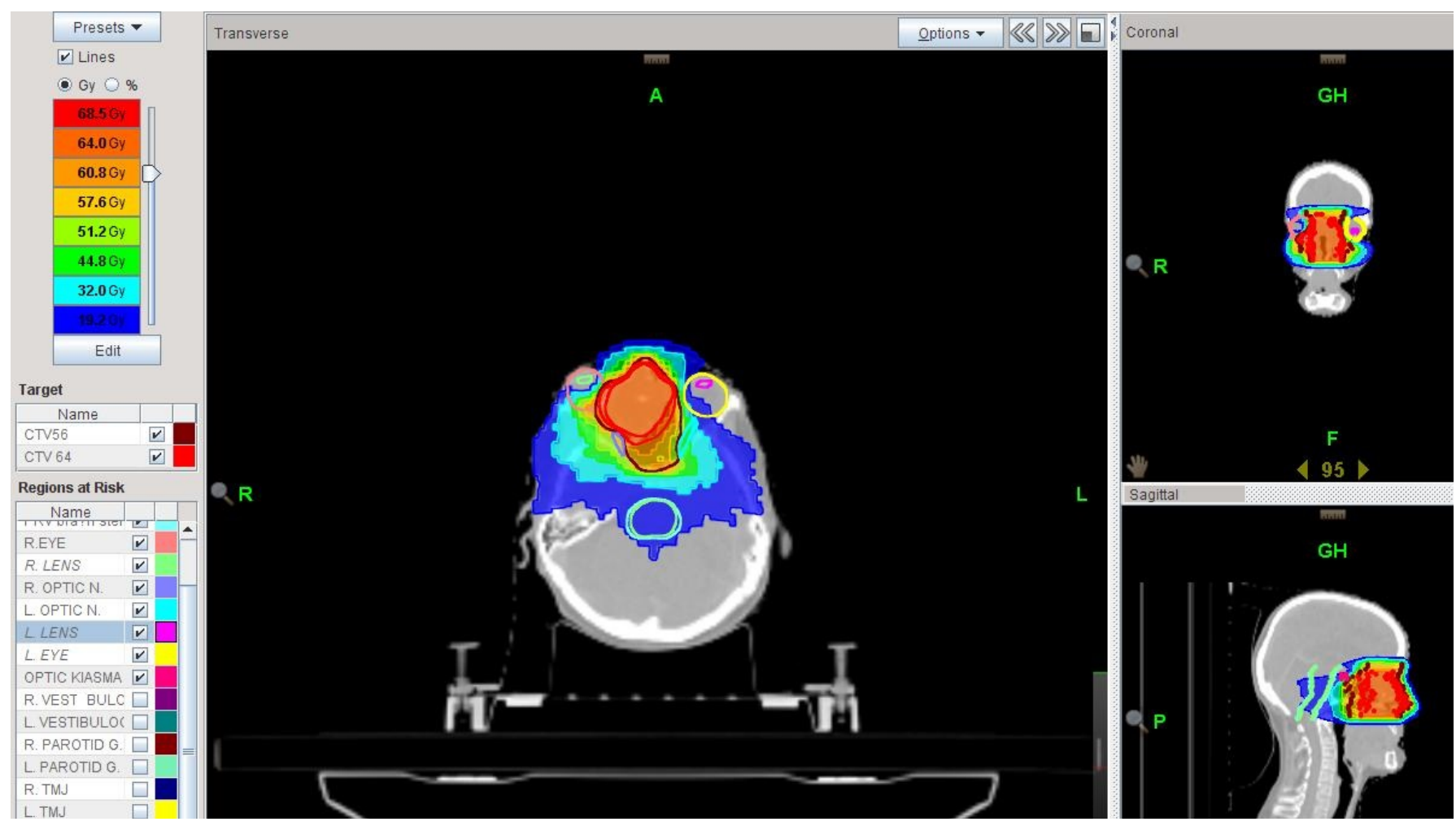

Figure 3. Helical tomotherapy planning dose distribution.

Table 1. Dosimetric parameters of planning target volume, PTV56 and OAR's.

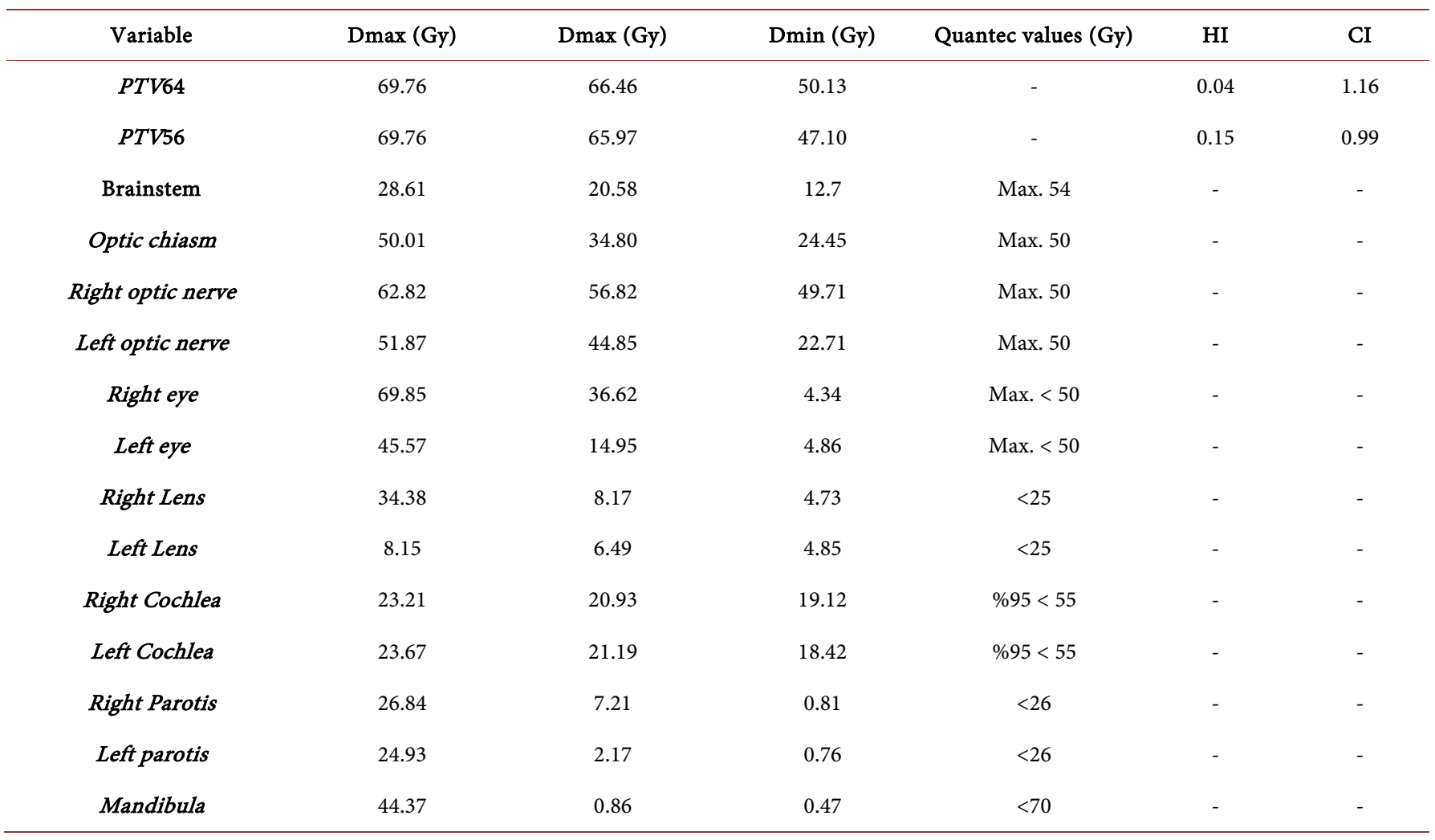



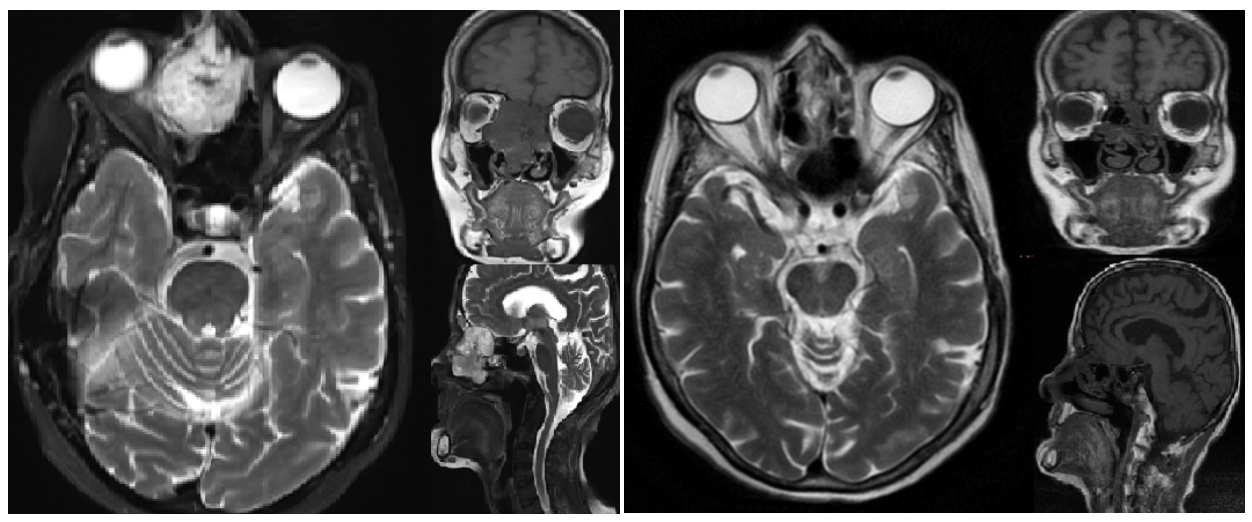

Figure 4. Image of the mass which completely responded to therapy as detected on MRI obtained at 6 and 18 months after helical tomotherapy.

progresses with nonspecific symptoms so diagnosis can be made only after onset of marked eye symptoms following invasion of the skull base or clinical signs signifying involvement of cranial nerves.

Surgical resection was accepted as a standard treatment for the treatment of head and neck CSs. Type of surgery depends on the histological grade, spread and location of the tumor. The objective of surgery is to perform gross total resection so as to obtain a tumor-free surgical margin. However, in tumors involving skull base, achievement of tumor-free surgical margin could not be ensured in most of the cases [11] [12].

Effectiveness of radiotherapy in these patients as a monotherapy has been reported and applicability of radiotherapy has been indicated if radical surgery is the only curative alternative [8]. In conclusion radiotherapy can be used for postsurgical residues, palliation of unresectable tumors or patients not suitable for major surgery. Also our patient was considered as an inoperable case because of tumor invasion into the right orbita and skull base, so radiotherapy was applied.

Various arguments exist about CSs localized on HN region. Since this tumor slowly progresses and consists of cartilage and connective tissue, it has a low level of radiosensitivity and it is considered relatively radioresistant. We also know that these types of tumors have smaller $\alpha / \beta$ ratios and yield a quadratic and delayed response to radiotherapy.

In our case, although clinical improvement was detected at an early time from treatment, radiological response manifested itself on MRI obtained at 18 month with marked regression in the dimensions of the lesion (Figure 4). As a result, radiotherapy is frequently used for cases not amenable to surgical excision or cases with surgical margin positivity. In a study by Sahgal et al. the researchers followed up 18 patients with CS treated with IG-IMRT method and reported 5-year overall survival and local control rates as $87.8 \%$ and $88.1 \%$, respectively [6].

IG-IMRT method using HT enables treatment of the patients. As another modality of External Beam Radiation Therapy, Proton Beam Radiation Therapy, which utilizes therapeutic effects of accelerated proton particles, is used successfully in the treatment of the tumors of paranasal sinus and skull base. In the future, Intensity Modulated Pro- 
ton Therapy (IMPT) technique can enable the treatment of head, neck and skull base tumors [7].

\section{Conclusion}

In our study, we performed in patients with diagnosis of low-grade CS of head and neck region who have not any chance of surgery because of its close vicinity to critical organs; we recommend application of IG-IMRT method using HT device.

\section{Acknowledgements}

The English in this document has been checked by at least two professional editors, both native speakers of English.

\section{References}

[1] Magnano, M., Boffano, P., Machetta, G., Garibaldi, E., Delmastro, E. and Gabriele, P. (2015) Chondrosarcoma of the Nasal Septum. European Archives of Oto-Rhino-Laryngology, 272, 765-772. http://dx.doi.org/10.1007/s00405-014-3419-2

[2] Gadwal, S.R., Fanburg-Smith, J.C., Gannon, F.H. and Thompson, L.D. (2000) Primary Chondrosarcoma of the Head and Neck in Pediatric Patients: A Clinicopathologic Study of 14 Cases with a Review of the Literature. Cancer, 88, 2181-2188. http://dx.doi.org/10.1002/(SICI)1097-0142(20000501)88:9<2181::AID-CNCR26>3.0.CO;2-6

[3] Lichtenstein, L. and Jaffe, H.L. (1943) Chondrosarcoma of Bone. American Journal of Pathology, 19, 553-573.

[4] Harwood, A.R., Krajbich, J.I. and Fornasier, V.L. (1980) Radiotherapy for Chondrosarcoma of Bone. Cancer, 45, 2769-2777.

http://dx.doi.org/10.1002/1097-0142(19800601)45:11<2769::AID-CNCR2820451111>3.0.C $\mathrm{O} ; 2-\mathrm{X}$

[5] McNaney, D., Lindberg, R.D., Ayala, A.G., Barkley, H.T. and Hussey, D.H. (1982) Fifteen Year Radiotherapy Experience with Chondrosarcoma of Bone. International Journal of Radiation Oncology ${ }^{*}$ Biology ${ }^{*}$ Physics, 8, 187-190.

http://dx.doi.org/10.1016/0360-3016(82)90512-0

[6] Sahgal, A., Chan, M.W., Atenafu, E.G., Masson-Cote, L., Bahl, G., Yu, E., Millar, B.A., et al. (2015) Image-Guided, Intensity-Modulated Radiation Therapy (IG-IMRT) for Skull Base Chordoma and Chondrosarcoma: Preliminary Outcomes. Neuro-Oncology, 17, 889-894. http://dx.doi.org/10.1093/neuonc/nou347

[7] Holliday, E.B. and Steven, S.J. (2014) Proton Radiation Therapy for Head and Neck Cancer: A Review of the Clinical Experience to Date. International Journal of Radiation Oncology * Biology ${ }^{*}$ Physics, 89, 292-302. http://dx.doi.org/10.1016/j.ijrobp.2014.02.029

[8] Austin-Seymour, M., Munzenrider, J., Goiten, M., et al. (1989) Fractionated Proton Radiation Therapy of Chordoma and Low Grade Chondrosarcoma of the Base of the Skull. Journal of Neurosurgery, 70, 13-17. http://dx.doi.org/10.3171/jns.1989.70.1.0013

[9] Murthy, V., Master, Z., Gupta, T., Ghosh-Laskar, S., Budrukkar, A., Phurailatpam, R., Agarwal, J., et al. (2010) Helical Tomotherapy for Head and Neck Squamous Cell Carcinoma: Dosimetric Comparison with Linear Accelerator-Based Step-and-Shoot IMRT. Journal of Cancer Research and Therapeutics, 6, 194-198.

http://dx.doi.org/10.4103/0973-1482.65245 
[10] Coca-Pelaz, A., Rodrigo, J.P., Triantafyllou, A., Hunt, J.L., Fernández-Miranda, J.C., Strojan, P., de Bree, R., et al. (2014) Chondrosarcomas of the Head and Neck. European Archives of Oto-Rhino-Laryngology, 271, 2601-2609.

[11] Austin-Seymour, M., Munzenrider, J., Goiten, M., et al. (1989) Fractionated Proton Radiation Therapy of Chordoma and Low Grade Chondrosarcoma of the Base of the Skull. Journal of Neurosurgery, 70, 13-17. http://dx.doi.org/10.3171/jns.1989.70.1.0013

[12] Mavroidis, P., Ferreira, B.C., Shi, C., Lind, B.K. and Papanikolaou, N. (2007) Treatment Plan Comparison between Helical Tomotherapy and MLC-Based IMRT Using Radiobiological Measures. Physics in Medicine and Biology, 52, 3817-3836.

http://dx.doi.org/10.1088/0031-9155/52/13/011

Submit or recommend next manuscript to SCIRP and we will provide best service for you:

Accepting pre-submission inquiries through Email, Facebook, LinkedIn, Twitter, etc. A wide selection of journals (inclusive of 9 subjects, more than 200 journals)

Providing 24-hour high-quality service

User-friendly online submission system

Fair and swift peer-review system

Efficient typesetting and proofreading procedure

Display of the result of downloads and visits, as well as the number of cited articles

Maximum dissemination of your research work

Submit your manuscript at: http://papersubmission.scirp.org/

Or contact ijmpcero@scirp.org 